\title{
TENDÊNCIAS ANATÔMICAS NA FLORA SUL-RIO-GRANDENSE 2 - PARÊNQUIMA AXIAL ${ }^{1}$
}

\author{
SIDINEI RODRIGUES DOS SANTOS ${ }^{2}$
}

\section{RESUMO}

No presente estudo são discutidas as tendências anatômicas no parênquima axial das madeiras sul-riograndenses. Foram investigadas 123 espécies, 81 gêneros e 32 famílias de Angiospermas de ocorrência natural no Rio Grande do Sul. Os dados foram extraídos, basicamente, de artigos publicados entre os anos de 1980 e 2019. Observou-se uma grande variabilidade no parênquima axial das espécies, incluindo desde a completa ausência até os diversos padrões de distribuição apo e paratraqueais. O parênquima é predominantemente do tipo paratraqueal, seriado. $\mathrm{O}$ arranjo difuso e/ou difuso-em-agregados é o mais comuns. A altura do parênquima axial geralmente não ultrapassa 8 células e $500 \mu \mathrm{m}$, sendo as séries com mais de 4 células um pouco mais frequentes que as demais. O parênquima escasso mostrou-se mais comum que o abundante, mas na maioria das espécies a quantidade é intermediária. Cristais são muito frequentes, associados principalmente ao parênquima axial e/ou raios. Esta característica, juntamente com o parênquima paratraqueal e seriado, foram as únicas que ocorreram em $50 \%$ ou mais das espécies investigadas. Do ponto de vista taxonômico, destacam-se os cristais em fibras, o parênquima ausente ou raro, as células oleíferas, drusas e cristais aciculares, bem como o parênquima fusiforme e marginal predominantes. Embora haja divergências, como no caso da incidência de cristais, os padrões observados refletem, via de regra, tendências anatômicas condizentes com o posicionamento latitudinal do Estado. As diferenças observadas podem ser atribuídas, ao menos em parte, a questões relacionadas à amostragem e/ou composição florística local.

Palavras-chave: Anatomia da madeira, anatomia ecológica, parênquima axial.

\section{ABSTRACT \\ [Anatomical trends in Rio Grande do Sul state flora 2 - Axial parenchyma].}

This paper aimed to identify anatomical trends in axial parenchyma of Rio Grande do Sul state woods, Brazil. Were investigated 123 species and 81 genera belonging to 32 families of Angiosperms Dicotyledons. The analyzed data were obtained, basically, from papers published between 1980 and 2019. There was a great variation in axial parenchyma features, ranging from completely absent to the various apotracheal and paratracheal types. Axial parenchyma was predominantly paratracheal and seriated, with apotracheal diffuse and/or diffuse-in-aggregate arrangement being the most common. Parenchyma strands usually did not exceed 8 cells and $500 \mu \mathrm{m}$, prevailing in this range those with more than 4 cells. Scarce was more common than abundant parenchyma, but in most species it was intermediary. Crystals are very common, associated mainly to the axial parenchyma and/or rays. This feature, together with paratracheal and seriated parenchyma, were the only ones that occurs at least $50 \%$ of the investigated species. From the taxonomic point of view, are very important the presence of crystals in fibres, axial parenchyma absent or rare, oil cells, druses and acicular crystals, as well as predominant fusiform or marginal parenchyma. Although exceptions do exist (eg. crystal incidence), the observed reflect, as a rule, anatomical trends matching with the latitudinal positioning of the Rio Grande do Sul state. Differences may be related, in part, to sampling and/or local floristic composition. Key words: Wood anatomy, ecological wood anatomy, axial parenchyma.

1 Recebido para publicação em 30/09/2019 e aceito para publicação em 01/11/2019.

2 Biólogo, Universidade Federal do Pampa (UNIPAMPA), Dom Pedrito, RS, Brasil. sthurt.bio@gmail.com 


\section{INTRODUÇÃO}

Os seres vivos à medida que se desenvolvem passam por mudanças fisiológicas, anatômicas e morfológicas que tendem a produzir um organismo adulto com aspecto e proporções características de sua espécie. Essa tendência, porém, permite variações entre os indivíduos de uma maneira aparentemente moldada pelas condições externas que acompanham o seu desenvolvimento, de modo que os diversos níveis de organização devem encontrar-se harmonizados com o ambiente físico e biológico ao redor. Isso é especialmente relevante no caso das plantas que, devido ao modo de vida séssil, não podem locomover-se em busca de melhores condições de crescimento, restando como única alternativa de sobrevivência a adaptação ao ambiente.

Com vistas a compreender o comportamento adaptativo do xilema secundário, que possibilita às plantas sobreviver em condições ambientais diversas, inúmeros estudos de Anatomia Ecológica têm sido desenvolvidos, sobretudo nas últimas décadas do século vinte: Baas (1973), Baas et al. (1983), Barajas-Morales (1985), Carlquist e Hoekman (1985), Baas e Schweingruber (1987), Wheeler e Baas (1991), Lindorf (1994), Alves e Angyalossy-Alfonso (2000) e León (2005). A maior parte desses estudos dedica-se à análise do sistema condutor de água e sais, tanto pela importância desse sistema para a árvore quanto pela grande variação na disponibilidade hídrica observada em diferentes ambientes. Em consequência, outros tecidos, embora igualmente importantes para a planta, tais como parênquima axial, raios e fibras, carecem, ainda, de maiores esclarecimentos. Alguns trabalhos, todavia, têm sido realizados nesse sentido, destacando-se, pela abrangência, os estudos de Alves e AngyalossyAlfonso (2002) sobre a flora brasileira e de Wheeler e Baas (1991) e Wheeler et al. (2007) sobre a mundial.

O parênquima axial, foco do presente estudo, é um tecido vivo, com orientação vertical, originado no câmbio vascular pela subdivisão das iniciais fusiformes, cuja principal função na madeira é o armazenamento e mobilização de substâncias, especialmente carboidratos. Pode atuar também de maneira subsidiária como um tecido de transporte a curtas distâncias ou de reserva de água e sais minerais, papel que chega a ser evidente em certos casos, como na paineira (Ceiba speciosa), na barriguda (Cavanillesia umbelata) e diversas outras espécies nativas e exóticas com estrutura anatômica especializada para este fim. Tende a ser paratraqueal e mais abundante nos trópicos do que nas regiões extratropicais, onde é apotraqueal e mais escasso, generalização que se aplica inclusive ao Brasil (Baas, 1982; Wheeler e Baas, 1991; Angyalossy-Alfonso, 2002; Wheeler et al., 2007). Do ponto de vista taxonômico, constitui igualmente um dos mais importantes tecidos, tanto para a identificação quanto para a classificação vegetal, motivo pelo qual se justifica plenamente o seu estudo aprofundado.

No presente trabalho, que dá seguimento à pesquisa sobre tendências estruturais na flora sul-rio-grandense iniciada em 2010 (Santos e Marchiori, 2010), pretende-se reunir informações anatômicas acerca do parênquima axial das madeiras nativas no Estado, bem como reconhecer e discutir as tendências estruturais observadas, em relação ao verificado na flora brasileira e mundial.

\section{MATERIAIS E MÉTODOS}

Situado no extremo sul do Brasil, em zona extratropical, o Rio Grande do Sul tem clima predominantemente úmido, com precipitação média de 1.539 (1.162-2.162) mm e temperatura média anual de $17,9{ }^{\circ} \mathrm{C}$ (Maluf, 2000). As chuvas, presentes durante todo o ano, geralmente superam a evapotranspiração, havendo, todavia, forte sazonalidade na temperatura entre inverno e verão (Brasil, 1973). As formações vegetacionais do Estado incluem Floresta Densa, Floresta Estacional Decidual, Floresta Estacional Semidecidual e Floresta Ombrófila Mista, além de capões-de-mato e matas ciliares, 
onde vivem mais de 500 espécies de árvores e arbustos lenhosos (Marchiori, 2002; Sobral et al., 2006).

Para a realização do presente estudo, foram analisadas as principais características do parênquima axial de um percentual significativo das madeiras sul-rio-grandenses. Ao todo, foram investigadas 123 espécies, 81 gêneros e 32 famílias de Angiospermas Dicotiledôneas. Os dados qualitativos e quantitativos que serviram de base para o estudo foram obtidos, basicamente, de artigos científicos disponíveis na literatura, no período de 1980 a 2019. As características anatômicas das espécies são apresentadas na Tabela 1, em ordem alfabética de famílias e nomes científicos. Os trabalhos consultados, referidos na TABELA 1 (RB), encontram-se listados juntamente com as demais referências bibliográficas ao final do texto.

Foram avaliados os seguintes aspectos: presença ou ausência, tipo (fusiforme/seriado), arranjo, altura e abundância do parênquima axial, bem como a ocorrência e distribuição de cristais e outros caracteres anatômicos especiais por ventura presentes. Procurou-se agrupar os dados em categorias conforme o IAWA Committee (1989), motivo pelo qual pode haver alguma divergência em relação ao descrito nos trabalhos originais, especialmente os mais antigos, entre outras circunstâncias. Na análise da altura ou comprimento linear das séries parenquimáticas, foram utilizados os valores médios. No caso da abundância do parênquima axial, foram criadas três categorias, também com base em valores médios: Escasso (fração inferior a $10 \%$ do tecido lenhoso), Abundante (fração superior a $20 \%$ do tecido lenhoso) e Intermediário (fração de 10-20\% do tecido lenhoso). Nas poucas vezes em que a quantificação do parênquima axial não esteve disponível, a classificação foi realizada através da comparação com as demais espécies.

As fotomicrografias que ilustram os diversos detalhes anatômicos foram obtidas a partir de lâminas histológicas de espécies nativas no Estado, cedidas gentilmente pelo professor José
Newton Cardoso Marchiori, a quem o autor agradece.

\section{RESULTADOS}

Como se pode observar na Tabela 1 , as espécies sul-rio-grandenses exibem grande variabilidade no parênquima axial, incluindo desde a completa ausência até os diversos padrões de distribuição apo e paratraqueais, com um leve predomínio deste último tipo (Figura 3). Na maior parte das madeiras investigadas se observa parênquima exclusivamente do tipo seriado (65\%). Menos frequente, o parênquima fusiforme é encontrado na estrutura anatômica de $25 \%$ das espécies, sobretudo em Leguminosae, e sempre em associação com o primeiro tipo. Embora não ocorra de maneira exclusiva em nenhuma das madeiras sul-riograndenses amostradas, esse tipo de tecido parenquimático pode, por vezes, apresentar-se em proporções semelhantes ou até superar em quantidade o parênquima seriado, que é geralmente o tipo predominante. É o caso de Lonchocarpus nitidus, Prosopis nigra, Calliandra tweediei, Calliandra foliolosa e várias outras espécies nativas deste e de outros gêneros não incluídos no estudo, como Erythrina, por exemplo (Figura 4). Por fim, um pequeno grupo com cerca de 12 espécies ou $10 \%$ do total, tem parênquima axial ausente ou muito raro, com destaque para as Salicaceae.

Cerca de $50 \%$ das espécies em estudo apresentam parênquima paratraqueal, ao passo que o apotraqueal é registrado em $40 \%$ do total. Apesar deste predomínio, são os arranjos difusos os mais comuns nas madeiras sul-riograndenses. Frequentemente associados em maior ou menor proporção, o parênquima apotraqueal difuso e difuso-em-agregados aparecem como padrão principal ou exclusivo em $32 \%$ das espécies, percentual que se deve em grande parte ao grupo das Myrtaceae, onde ocorrem com extraordinária frequência. Além desses, estão também comumente associados os parênquimas paratraqueal vasicêntrico, aliforme e confluente, não raro formando faixas de lar- 
Tabela 1. Resumo das principais características do parênquima axial das espécies estudadas.

\begin{tabular}{|c|c|c|c|c|c|c|c|c|c|c|c|c|}
\hline Familia & Espécie & $\boldsymbol{A}$ & $A p t$ & Ptq & $F x$ & $M$ & $T$ & $H$ & $H \mu$ & $\%$ & $\mathrm{Cr}$ & $R B$ \\
\hline \multirow[t]{2}{*}{ Anacardiaceae } & Lithraea brasiliensis & & & $\mathrm{e}$ & & & $\mathrm{s}$ & & & $\mathrm{e}$ & rf & 5 \\
\hline & Schinus polygamus & & & e & & & s & & & e & $r$ & 5 \\
\hline \multirow[t]{3}{*}{ Apocynaceae } & Aspidosperma quebrachoblanco & & da & & & & $s$ & $2-6$ & 99 & i & r & 46 \\
\hline & Aspidosperma riedelii & & da & & & & s & $2-6$ & 398 & e & $p$ & 89 \\
\hline & Tabernaemontana catharinensis & $\mathrm{x}$ & & & & & & & & e & $f$ & 4 \\
\hline Aquifoliaceae & llex dumosa & & da & & & & s & & & e & $r$ & 5 \\
\hline \multirow[t]{3}{*}{ Asteraceae } & Baccharis dracunculifolia & & & $\mathrm{ev}$ & & & fs & 2 & 193 & $\mathrm{e}$ & r & 79 \\
\hline & Baccharis longoattenuata & & & vc & & & fs & 2 & & $\mathrm{i}$ & r & 82 \\
\hline & Heterothalamus alienus & & & $v$ & & & fs & $2-4$ & 165 & $\mathrm{i}$ & r & 88 \\
\hline Berberidaceae & Berberis laurina & $x$ & & & & & & & & $\mathrm{e}$ & & 73 \\
\hline Cannabaceae & Celtis pallida & & & ac & I & & s & $2-4$ & 131 & a & $\mathrm{pr}$ & 74 \\
\hline Bignoniaceae & Handroanthus pulcherrimus & & & ac & & $x$ & s & $2-3$ & & a & & 71 \\
\hline Celastraceae & Maytenus cassineformis & $x$ & & & & & & & & $\mathrm{e}$ & & 22 \\
\hline Combretacee & Terminalia australis & & & ac & e & $x$ & fs & $2-4$ & 388 & a & $\mathrm{pr}$ & 56 \\
\hline Ebenaceae & Maba inconstans & & da & & $\mathrm{e}$ & & s & $3-8$ & 350 & a & $\mathrm{pr}$ & 39 \\
\hline Escalloniaceae & Escallonia megapotamica & & d & & & & $s$ & & 168 & $\mathrm{i}$ & & 72 \\
\hline \multirow[t]{7}{*}{ Euphorbiaceae } & Bernardia pulchella & & & e & & & $s$ & $2-5$ & 431 & e & & 95 \\
\hline & Colliguaja brasiliensis & & d & & & & s & $2-5$ & 372 & $\mathrm{e}$ & & 102 \\
\hline & Croton dracunculoides & & & e & & & s & $2-6$ & 324 & e & $r$ & 97 \\
\hline & Croton pycnocephalus & & & e & & & $s$ & $2-5$ & 456 & e & & 97 \\
\hline & Sapium haematospermum & & da & & & & s & $2-4$ & 324 & $\mathrm{i}$ & r & 96 \\
\hline & Sebastiana schottiana & & d & & & & s & $4-8$ & & $\mathrm{e}$ & & 24 \\
\hline & Tetrorchidium rubrivenium & & d & & & & s & $3-7$ & 978 & $\mathrm{i}$ & & 29 \\
\hline \multirow[t]{21}{*}{ Fabaceae } & Acacia bonariensis & & & vac & & $x$ & fs & $2-5$ & 246 & $\mathrm{i}$ & $\mathrm{p}$ & 69 \\
\hline & Acacia caven & & & vac & I & $x$ & fs & $2-4$ & 198 & $\mathbf{a}$ & pr & 60 \\
\hline & Acacia ibirocayensis & & & vac & & $x$ & fs & $2-3$ & 175 & a & $\mathrm{p}$ & 62 \\
\hline & Acacia nitidifolia & & & vc & & $x$ & fs & $2-4$ & 374 & $\mathrm{e}$ & $p$ & 59 \\
\hline & Acacia recurva & & & vac & & $x$ & fs & $2-5$ & 119 & $\mathrm{i}$ & $\mathrm{p}$ & 37 \\
\hline & Acacia tucumanensis & & & ve & & $x$ & fs & $2-8$ & 290 & e & $\mathrm{p}$ & 63 \\
\hline & Albizia austrobrasilica & & & vac & & $x$ & s & $2-4$ & 376 & $\mathrm{i}$ & $p$ & 64 \\
\hline & Albizia inundata & & & c & I & & $s$ & $2-4$ & 358 & $\mathbf{a}$ & $\mathrm{p}$ & 10 \\
\hline & Calliandra foliolosa & & & va & I & & fs & 2 & 188 & a & $p$ & 42 \\
\hline & Calliandra tweediei & & & va & I & & fs & 2 & 263 & a & $\mathrm{p}$ & 42 \\
\hline & Cassia corymbosa & & & vc & & & fs & $2-4$ & 249 & $\mathrm{i}$ & r & 40 \\
\hline & Enterolobium contortisiliquum & & & vac & & & $s$ & & & a & $p$ & 31 \\
\hline & Indigofera suffruticosa & & & vac & & $x$ & fs & $2-4$ & 164 & $\mathrm{i}$ & $p$ & 51 \\
\hline & Lonchocarpus leucanthus & & & c & I & $x$ & fs & 2 & 184 & a & $\mathrm{p}$ & 54 \\
\hline & Lonchocarpus nitidus & & & c & I & $x$ & fs & 2 & 201 & a & $p$ & 48 \\
\hline & Mimosa berroi & & & $v$ & & $x$ & fs & 2 & 189 & $\mathrm{i}$ & $\mathrm{p}$ & 68 \\
\hline & Mimosa bimucronata & & & vac & & $x$ & fs & $2-4$ & 233 & $\mathrm{i}$ & $\mathrm{p}$ & 61 \\
\hline & Mimosa cruenta & & & $\mathrm{vc}$ & & & fs & $2-3$ & 268 & $\mathrm{i}$ & $\mathrm{p}$ & 44 \\
\hline & Mimosa daleoides & & & vac & & & fs & 2 & 271 & $\mathrm{i}$ & pr & 38 \\
\hline & Mimosa eriocarpa & & & $v$ & & & $s$ & $2-6$ & 205 & e & $\mathrm{p}$ & 21 \\
\hline & Mimosa incana & & & $v$ & & $x$ & fs & $2-4$ & 257 & $\mathrm{i}$ & $p$ & 66 \\
\hline
\end{tabular}




\begin{tabular}{|c|c|c|c|c|c|c|c|c|c|c|c|c|}
\hline & Mimosa pilulifera & & & V & & $\mathrm{x}$ & fs & $2-4$ & 281 & $\mathrm{i}$ & $p$ & 78 \\
\hline & Mimosa scabrella & & & va & & $x$ & fs & $2-3$ & 379 & i & & 65 \\
\hline & Mimosa sparsa & & & $\mathrm{v}$ & & $x$ & fs & 2 & 255 & e & $p$ & 34 \\
\hline & Mimosa trachycarpa & & & ve & & & fs & 2 & 183 & i & pr & 77 \\
\hline & Mimosa uraguensis & & & vc & & & fs & 2 & 259 & i & $p$ & 67 \\
\hline & Prosopis algarobilla & & & ac & & $x$ & fs & $2-3$ & 226 & a & $p$ & 45 \\
\hline & Prosopis nigra & & & ac & & $\mathrm{x}$ & fs & $2-3$ & 199 & a & $p$ & 45 \\
\hline Lauraceae & Ocotea pulchella & & & ev & & & s & & & i & & 5 \\
\hline Lythraceae & Lafoensia nummulariifolia & $x$ & & & & & & & & e & & 90 \\
\hline Meliaceae & Guarea lessoniana & & & ac & & & s & $2-8$ & 531 & a & $p$ & 43 \\
\hline & Trichilia hieronymii & & & vac & e & $x$ & s & $2-9$ & 383 & i & $r$ & 55 \\
\hline Moraceae & Ficus cestrifolia & & & & 1 & & s & $4-8$ & & a & pr & 84 \\
\hline & Maclura tinctoria & & & vac & & $x$ & s & $2-7$ & 368 & e & pr & 35 \\
\hline & Sorocea bonplandii & & & c & 1 & & $s$ & & & a & & 27 \\
\hline Myrtaceae & Acca sellowiana & & da & & & & s & $3-6$ & 414 & i & $p$ & 92 \\
\hline & Blepharocalyx salicifolius & & $\mathrm{da}$ & & & & s & $2-8$ & 445 & a & $p$ & 92 \\
\hline & Calyptranthes concinna & & $\mathrm{da}$ & & & & s & $4-8$ & 526 & a & & 92 \\
\hline & Calyptranthes tricona & & da & & e & & s & $2-8$ & 431 & $\mathrm{i}$ & & 92 \\
\hline & Campomanesia aurea & & $\mathrm{da}$ & & & & s & $2-4$ & 294 & a & & 92 \\
\hline & Campomanesia rhombea & & $\mathrm{da}$ & & & & s & $2-4$ & 404 & i & & 92 \\
\hline & Campomanesia xanthocarpa & & $\mathrm{da}$ & & & & s & $2-8$ & 458 & a & & 92 \\
\hline & Eugenia burkartiana & & $\mathrm{da}$ & & & & s & $4-9$ & 547 & $\mathrm{i}$ & $p$ & 92 \\
\hline & Eugenia hiemalis & & da & & e & & s & $2-10$ & 462 & $\mathrm{i}$ & $p$ & 92 \\
\hline & Eugenia involucrata & & $\mathrm{da}$ & & & & $s$ & $4-9$ & 583 & a & $p$ & 92 \\
\hline & Eugenia mansoi & & da & & e & & s & $4-11$ & 581 & $\mathrm{i}$ & $p$ & 92 \\
\hline & Eugenia rostrifolia & & $\mathrm{da}$ & & le & & s & $4-13$ & 547 & $\mathrm{i}$ & $p$ & 92 \\
\hline & Eugenia schuechiana & & $\mathrm{da}$ & & e & & s & $4-10$ & 710 & $\mathrm{i}$ & $p$ & 92 \\
\hline & Eugenia unifiora & & da & & le & & s & $3-9$ & 402 & i & $p$ & 92 \\
\hline & Eugenia uruguayensis & & da & & & & s & $2-8$ & 538 & $\mathrm{i}$ & $p$ & 92 \\
\hline & Gomidesia palustris & & d & & & & s & $3-8$ & 556 & i & & 92 \\
\hline & Hexachlamys edulis & & da & & le & & s & $4-14$ & 550 & $\mathrm{i}$ & $p$ & 92 \\
\hline & Myrceugenia euosma & & da & & & & s & $3-8$ & 432 & i & & 92 \\
\hline & Myrceugenia glaucescens & & da & & & & s & $4-8$ & 592 & a & & 92 \\
\hline & Myrceugenia miersiana & & $\mathrm{da}$ & & & & s & $4-8$ & 592 & a & & 92 \\
\hline & Myrceugenia myrtoides & & da & & & & s & $4-8$ & 498 & i & & 92 \\
\hline & Myrcia bombycina & & da & & & & s & $2-5$ & 432 & a & & 92 \\
\hline & Myrcia selloi & & da & & & & s & $2-8$ & 680 & $\mathrm{i}$ & $p$ & 92 \\
\hline & Myrcianthes cisplatensis & & $\mathrm{da}$ & & & & s & $4-8$ & 439 & $\mathrm{i}$ & $p$ & 92 \\
\hline & Myrcianthes gigantea & & $\mathrm{da}$ & & & & s & $4-9$ & 552 & $\mathrm{i}$ & & 92 \\
\hline & Myrcianthes pungens & & $\mathrm{da}$ & & le & & s & $2-16$ & 444 & $\mathrm{i}$ & $p$ & 92 \\
\hline & Myrciaria cuspidata & & da & & & & s & $3-8$ & 407 & i & & 92 \\
\hline & Myrciaria tenella & & $\mathrm{da}$ & & & & s & $3-7$ & 424 & $\mathrm{i}$ & & 92 \\
\hline & Myrrhinium atropurpureum & & $\mathrm{da}$ & & e & & s & $3-8$ & 496 & i & $p$ & 92 \\
\hline & Plinia rivularis & & da & & & & s & $7-11$ & 528 & a & $p$ & 92 \\
\hline & Plinia trunciflora & & da & & & & s & $2-8$ & 355 & a & $p$ & 92 \\
\hline & Psidium cattleianum & & da & & & & s & $2-9$ & 764 & a & $p$ & 92 \\
\hline
\end{tabular}




\begin{tabular}{|c|c|c|c|c|c|c|c|c|c|c|c|c|}
\hline & Siphoneugena reitzii & & da & & & & $\mathrm{s}$ & $2-4$ & 287 & $\bar{i}$ & & 92 \\
\hline Nyctaginaceae & Guapira opposita & & & $\mathrm{e}$ & & & & & & e & & 5 \\
\hline Phyllanthaceae & Phyllanthus sellowianus & $x$ & & & & & & & & e & & 24 \\
\hline \multirow[t]{2}{*}{ Polygonaceae } & Coccoloba cordata & & $d$ & e & & & s & $2-5$ & 220 & $\mathrm{i}$ & $\mathrm{pf}$ & 75 \\
\hline & Ruprechtia salicifolia & & & e & & & s & $2-7$ & 307 & e & $f$ & 93 \\
\hline Quillajaceae & Quillaja brasiliensis & & da & & & & $s$ & $2-4$ & 343 & a & & 41 \\
\hline \multirow[t]{5}{*}{ Rhamnaceae } & Colletia paradoxa & & & $\mathrm{e}$ & & & s & $2-4$ & 225 & e & $r$ & 81 \\
\hline & Colubrina glandulosa & & & $\mathrm{e}$ & & & s & $2-5$ & 246 & $\mathrm{i}$ & $\mathrm{pr}$ & 103 \\
\hline & Condalia buxifolia & & & e & & & s & $3-6$ & 261 & e & $r$ & 11 \\
\hline & Rhamnus sphaerosperma & & & e & & & $s$ & $2-8$ & 389 & e & $r$ & 81 \\
\hline & Scutia buxifolia & & & ev & & $x$ & s & $3-8$ & 266 & i & $r$ & 81 \\
\hline \multirow[t]{5}{*}{ Rubiaceae } & Cephalanthus glabratus & & $d$ & e & & & $s$ & $2-5$ & 370 & e & & 94 \\
\hline & Chomelia obtusa & $x$ & & & & & s & $2-3$ & & e & & 49 \\
\hline & Guettarda uruguensis & $x$ & & & & & & & & e & & 52 \\
\hline & Machaonia spinosa & & & e & & & s & $2-4$ & 249 & e & & 76 \\
\hline & Randia armata & & $d$ & & & & $s$ & $2-7$ & 520 & e & & 58 \\
\hline \multirow[t]{2}{*}{ Rutaceae } & Helietta longifoliata & & & e & & $x$ & fs & $2-4$ & 299 & e & $p$ & 53 \\
\hline & Pilocarpus pennatifolius & & & & le & $x$ & s & $2-4$ & 289 & $\mathrm{i}$ & & 50 \\
\hline \multirow[t]{4}{*}{ Salicaceae } & Azara uruguayensis & $x$ & & & & & & & & e & $r$ & 25 \\
\hline & Casearia sylvestris & $x$ & & & & & & & & e & $r$ & 5 \\
\hline & Salix humboldtiana & $x$ & & & & $x$ & s & $2-3$ & & e & & 26 \\
\hline & Xylosma tweedianum & $x$ & & & & & & & & e & & 80 \\
\hline Santalaceae & Acanthosyris spinescens & & $d$ & e & & $x$ & fs & $2-4$ & 230 & e & $r$ & 47 \\
\hline Sapindaceae & Allophylus guaraniticus & & & e & & & s & $3-5$ & 365 & e & $f$ & 98 \\
\hline \multirow[t]{2}{*}{ Sapotaceae } & Chrysophyllum marginatum & & & & e & & & & & $\mathrm{i}$ & & 5 \\
\hline & Pouteria salicifolia & & & & I & & s & $2-7$ & 387 & i & & 57 \\
\hline \multirow[t]{2}{*}{ Solanaceae } & Brunfelsia australis & & $d$ & & & & s & $2-5$ & 331 & e & & 101 \\
\hline & Cestrum strigillatum & $x$ & & & & & & & & $\mathrm{e}$ & $r$ & 114 \\
\hline \multirow[t]{4}{*}{ Verbenaceae } & Aloysia chamaedryfolia & & & e & & & $s$ & $2-4$ & 316 & $\mathrm{e}$ & & 99 \\
\hline & Aloysia gratíssima & & & e & & & $s$ & $2-6$ & 262 & e & & 99 \\
\hline & Citharexylum montevidense & & & e & & $x$ & s & $2-4$ & 341 & e & & 100 \\
\hline & Cytharexylum solanaceum & & & e & & & s & $2-4$ & 283 & $\mathrm{e}$ & & 28 \\
\hline Vochysiaceae & Callisthene inundata & & & & 1 & & s & $2-4$ & 337 & a & $\mathrm{pr}$ & 104 \\
\hline
\end{tabular}

$\mathrm{A}=$ parênquima axial ausente ou raro. $\mathrm{Apt}=$ parênquima apotraqueal: $d$, difuso; $d a$, difuso-em-agregados. Ptq= parênquima paratraqueal: $e$, escasso; $v$, vasicêntrico; $a$, aliforme; $c$, confluente. $\mathrm{Fx}=$ parênquima em faixas ou linhas: $e$, estreitas, até três células de largura; $l$, largas, mais de três células de largura. $\mathrm{M}=$ parênquima em faixas ou linhas marginais: $x$, caráter presente. $\mathrm{T}=$ tipo de parênquima axial: $s$, seriado; $f$, fusiforme. $\mathrm{H}=$ altura das séries parenquimáticas em número de células. $\mathrm{H} \mu=$ altura em micrômetros. \%= quantidade de tecido parenquimático na madeira: $e$, escasso; $i$, intermediário, $a$, abundante. $\mathrm{Cr}=$ presença de cristais: $r$, nos raios; $p$, no parênquima axial; $f$, nas fibras. $\mathrm{RB}=$ referência bibliográfica que deu origem aos dados. A numeração indica o seu posicionamento na literatura consultada ao final do trabalho. Obs.: Campos sem preenchimento indicam caráter ausente ou não disponível. No caso do arranjo do parênquima axial, foram anotados apenas os tipos mais representativos. 
gura e comprimento variáveis, até contínuas, por vezes (Tabela 1). Esses tipos de parênquima compõem, em conjunto, o segundo padrão de distribuição mais frequente, ocorrendo em cerca de $27 \%$ das espécies estudadas, percentual que se deve principalmente às Leguminosas.

É comum estarem associados a esses padrões outros tipos menos conspícuos, especialmente o paratraqueal escasso, como se pode observar nos diversos gêneros e espécies dessas mesmas famílias. Como padrão exclusivo ou principal, o parênquima paratraqueal escasso ocorre, todavia, na estrutura anatômica de apenas $16 \%$ do total, com destaque, neste estudo, para Rhamnaceae. Incluindo os diferentes tipos, 19\% das espécies têm parênquima axial em faixas, que podem ocorrer tanto em associação aos vasos, como em Callisthene inundata, Celtis pallida, Terminalia australis e nas Leguminosae de modo geral, quanto independentemente deles, caso das Myrtaceae e Sapotaeae, entre outras. Parênquima marginal é anotado para $24 \%$ do total, podendo apresentar-se de maneira sutil, como em Helietta apiculata e Salix humboldtiana, ou mais conspícua, como em Handroanthus pulcherrimus, Scutia buxifolia e diversas espécies de Leguminosae, onde é especialmente comum. Embora o parênquima marginal ocorra, via de regra, de forma subsidiária aos diversos tipos de parênquima paratraqueal, em alguns casos ele pode aparecer como o tipo mais representativo na madeira, a exemplo de Pilocarpus pennatifolius (Figura 3). Outra espécie que ilustra bem essa situação é Cedrela fissilis, cuja madeira está entre as mais conhecidas e valiosas do Estado. $\mathrm{O}$ cedro, todavia, não integra o rol das espécies estudadas.

Em relação às características quantitativas, cerca de $24 \%$ das espécies gaúchas têm parênquima axial abundante (fração>20\%), percentual bastante inferior ao contingente com parênquima ausente/raro ou escasso $(<10 \%)$, que gira em torno de $34 \%$. As demais, por conseguinte, exibem quantidades intermediárias deste tecido e constituem a maioria. A ocorrência de parênquima axial abundante é comum em espécies com parênquima paratraqueal confluente e/ou em faixas largas que costumam ocupar grande parte do volume da madeira, mas não é uma exclusividade desses grupos, como se pode observar na Tabela 1. Em Myrtaceae, por exemplo, onde predomina o padrão difuso-emagregados, também é considerável a quantidade de espécies com tecido parenquimático abundante, embora com valores geralmente um pouco mais modestos em relação aos que podem alcançar as espécies com parênquima confluente e/ou em faixas largas, como algumas Leguminosas (ex. Prosopis, Lonchocarpus, Calliandra).

A escassez de parênquima axial, por sua vez, ocorre sobretudo em taxas que apresentam parênquima difuso e/ou paratraqueal escasso, salientando-se, neste estudo, as Euphorbiaceae, Rhamnaceae e Rubiaceae, além das Salicaceae, cujo parênquima axial é muito raro ou completamente ausente. A altura das séries de parênquima axial raramente ultrapassa 8 células e $500 \mu \mathrm{m}$, exceto em Myrtaceae, que é a família com a maior altura média registrada $(496 \mu \mathrm{m})$. A de menor altura é Leguminosae $(244 \mu \mathrm{m})$, considerando-se apenas aquelas com maior número de representantes (Tabela 1). Dentro do referido intervalo, as séries com até 2 ou 4 células são um pouco menos frequentes do que aquelas com mais de 4 células de altura (10\%, $27 \%$ e $37 \%$, respectivamente).

Também é anotada a ocorrência de células oleíferas e cristais nas madeiras sul-riograndenses (Figura 2,4). Muito frequentes, os cristais estão presentes em 76 das 123 espécies em estudo (61\%), notadamente em Fabaceae, Myrtaceae e Rhamnaceae (Tabela 1). São, via de regra, do tipo prismáticos, mas também podem apresentar-se eventualmente de outras formas, como drusas (Acanthosyris spinescens, Colubrina glandulosa) e cristais aciculares (Baccharis e Heterothalamus). No material investigado, os cristais encontraram-se associa- 


\section{Parênquima axial}

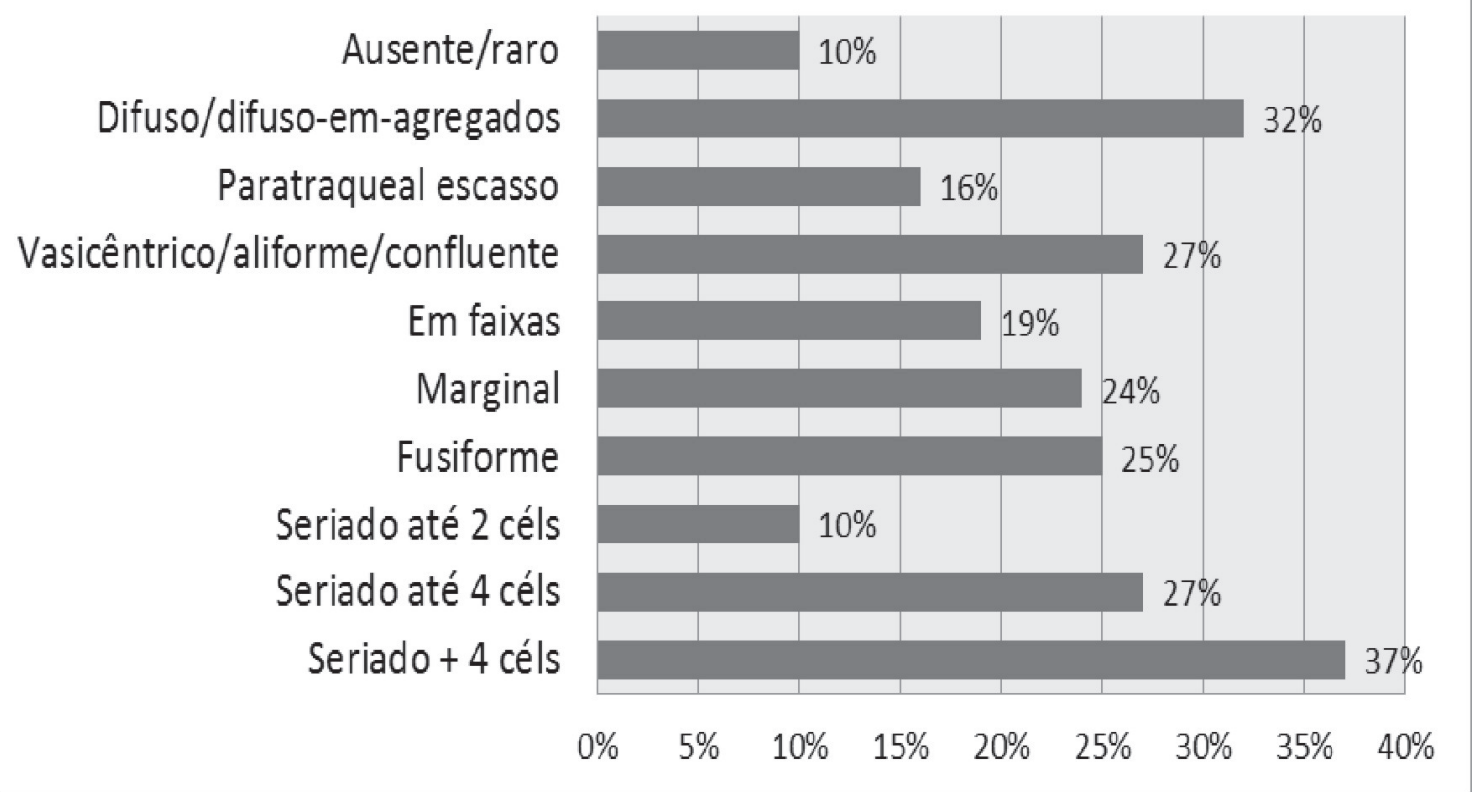

FIGURA 1 - Incidência das principais características do parênquima axial na flora sul-rio-grandense.

dos principalmente ao parênquima axial (44\%) e/ou raios $(23 \%)$, sendo muito pouco comum no interior das fibras septadas (4\%). Ao contrário dos cristais, que são muito frequentes, as células oleíferas aparecem apenas na estrutura anatômica de Ocotea pulchella. Comum em Lauraceae, a ocorrência desse tipo peculiar de célula é limitada a um pequeno número de taxa, com destaque para as canelas, como são vulgarmente conhecidas no Brasil as espécies dos gêneros Nectandra e Ocotea. Os oleíferos, vale lembrar, podem estar presentes tanto no parênquima axial quanto nos raios.

\section{DISCUSSÃO}

O predomínio de espécies com parênquima axial do tipo seriado está de acordo com o referido na literatura, embora com percentuais um pouco divergentes. De acordo com Wheeler et al. (2007), apenas 6\% das espécies da flora mundial apresentam parênquima fusiforme, podendo chegar a $10 \%$ nas regiões Temperadas da América do Sul. Esses valores não diferem muito do calculado para flora tropical brasileira (Barros e Callado, 1997; Barros et al., 2001, 2003; Trevizor, 2011; Silva, 2013), mas são muito distintos em relação à sul-rio-grandense, onde o quantitativo de espécies com parênquima fusiforme chega a $25 \%$. A maior incidência de espécies com parênquima fusiforme no presente estudo explica-se pelo grande número de representantes de Leguminosae amostrados. Como comentam Wheeler et al. (1989), células fusiformes são particularmente comuns em madeiras com estrutura estratificada e/ou elementos axiais curtos, caso típico das Leguminosae e de outras famílias com estrutura anatômica evoluída, como Bignoniaceae e Asteraceae. De fato, quase todas as espécies com parênquima fusiforme investigadas têm também séries parenquimáticas curtas, de até 4 células de altura (Tabela 1). 


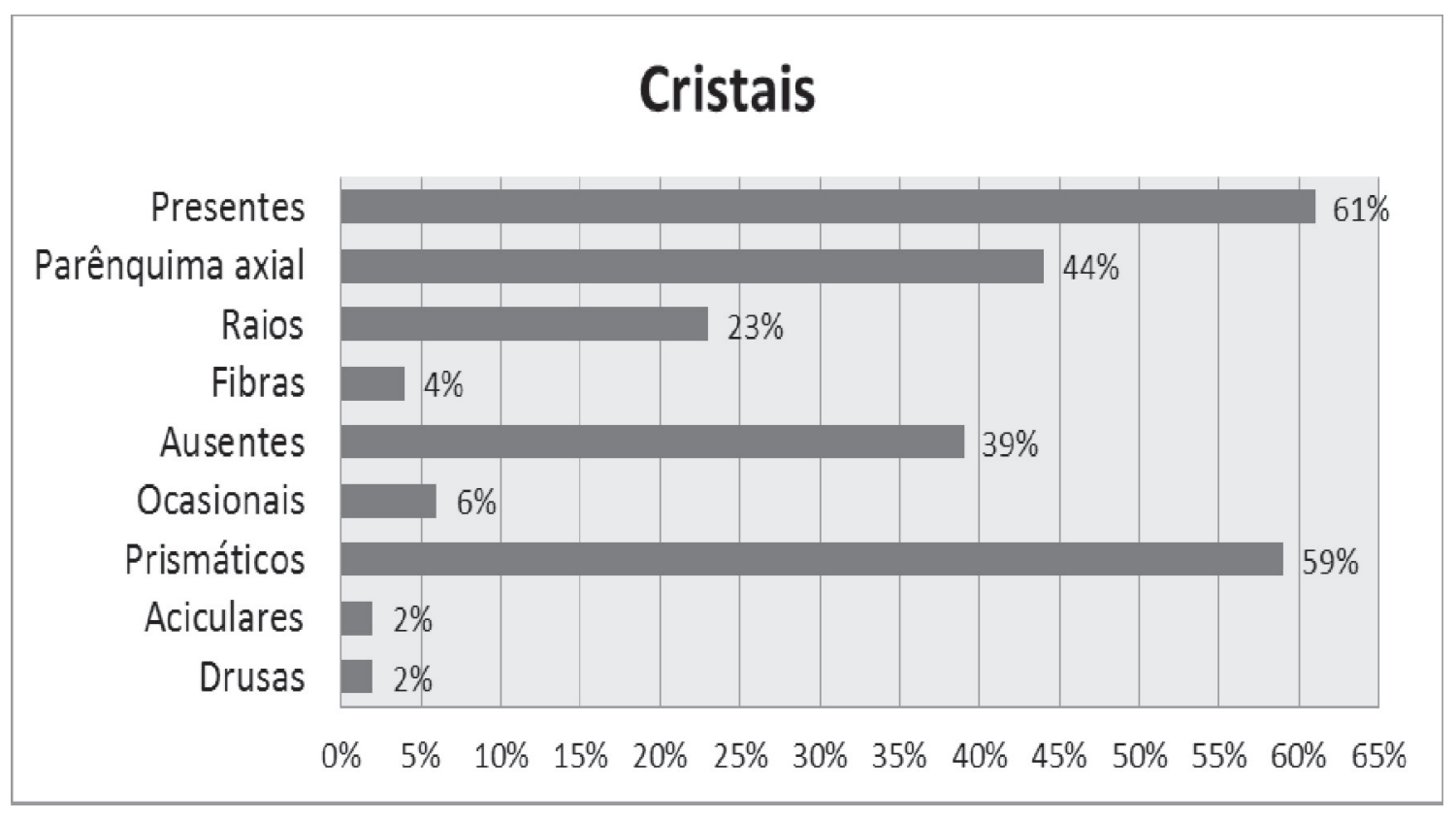

FIGURA 2 - Frequência de cristais nas madeiras sul-rio-grandenses.

No tocante à distribuição do parênquima axial, embora os arranjos difuso e/ou difuso-emagregados tenham sido os mais frequentes, de modo geral observou-se maior incidência dos padrões paratraqueais, em concordância com o que tem sido atribuído na literatura para a flora brasileira e mundial (Wheeler e Baas, 1991; Alves e Angyalossy-Alfonso, 2002; Wheeler et al., 2007). O percentual de espécies sul-riograndenses com parênquima paratraqueal, todavia, mostrou-se, via de regra, inferior ao encontrado em floras brasileiras de latitudes menores, ao contrário do parênquima apotraqueal, que apresentou valores mais elevados. No primeiro caso, quase sempre verificam-se percentuais superiores a $60 \%$, enquanto que, no segundo, os valores tendem a ficar próximos dos $30 \%$ ou menos (Barros e Callado, 1997; Barros et al., 2001, 2003; Mattos et al., 2003; Muñiz et al., 2007; Sonsin-Oliveira, 2010; Trevizor, 2011; Silva et al., 2013). Lembrando que, no Estado, esses números giraram em torno de $50 \%$ e $40 \%$, respectivamente. As maiores discrepâncias foram registradas em relação ao parênquima apotraqueal das floras das regiões Norte e Centro-Oeste, onde o quantitativo de espécies com esse tipo de tecido não excede $10 \%$. Embora com percentuais distintos, esse resultado vai ao encontro do observado por Alves e AngyalosssyAlfonso (2002).

As diferenças latitudinais apontadas corroboram igualmente o que tem sido referido na literatura. De acordo com Alves e AngyalossyAlfonso (2002) e Wheeler et al. (2007), em regiões extratropicais como o Rio Grande do Sul, é menor a quantidade de espécies com parênquima paratraqueal relativamente aos trópicos, seguindo os padrões apotraqueais um comportamento inverso. Em termos funcionais ou ecológicos, o predomínio do parênquima paratraqueal na região tropical pode estar relacionado a sua maior ou mais rápida capacidade de armazenamento e mobilização de água, açúcares e outras substâncias durante a estação de crescimento, bem como a questões relativas à segurança no transporte hídrico nestas áreas, onde as taxas fotossintéticas são elevadas (Braun, 1984; Carlquist, 2001). 


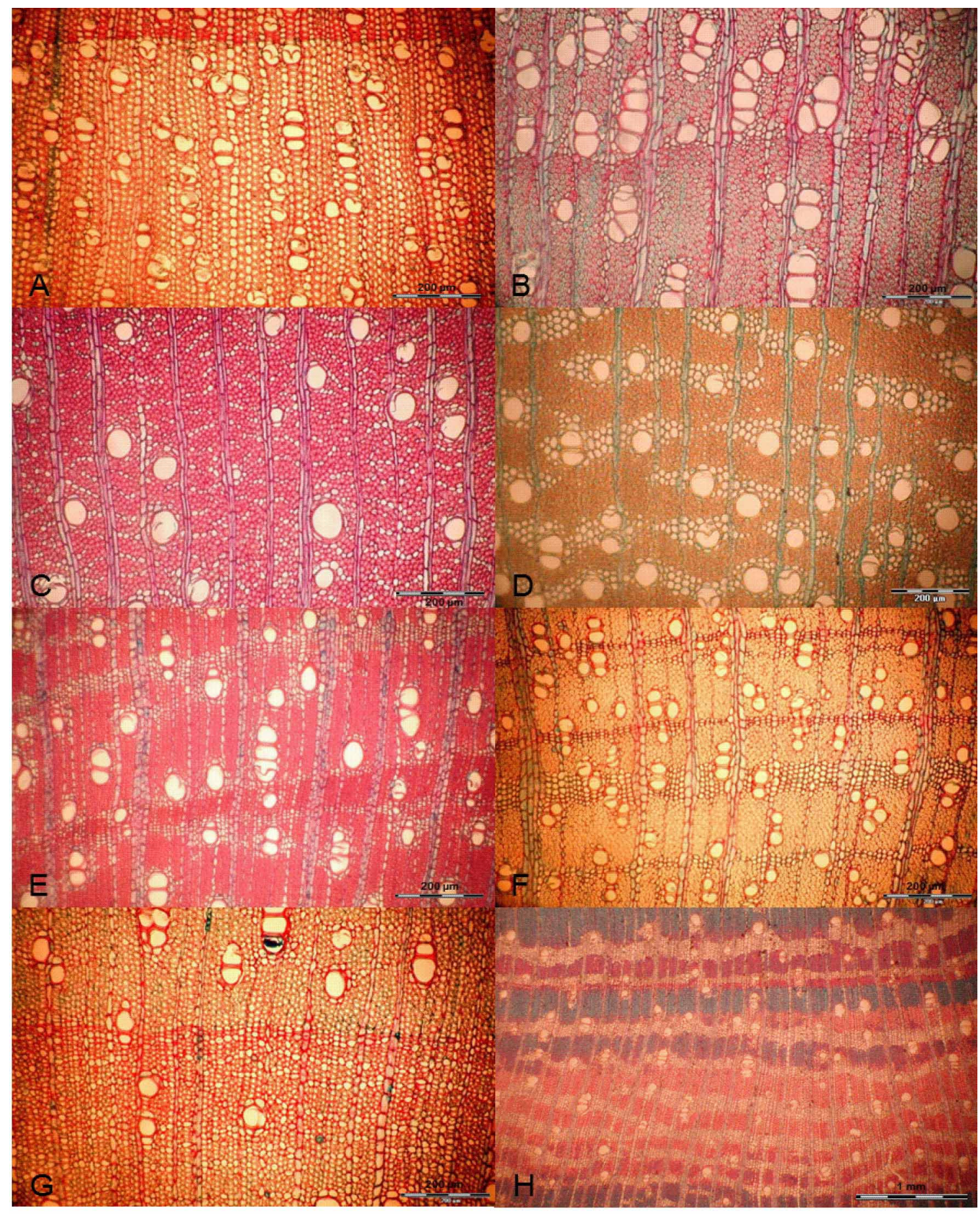

FIGURA 3 - Diversidade do parênquima axial nas madeiras sul-rio-grandenses. A- Parênquima axial ausente em Guettarda uruguensis. B- Parênquima paratraqueal escasso em Acanthosyris spinescens. C- Parênquima difuso e difuso-em-agregados em Aspidosperma quebrachoblanco. D- Parênquima aliforme confluente em Handroanthus pulcherrimus. EParênquima vasicêntrico escasso e marginal em Scutia buxifolia. F- Parênquima em faixas marginais largas e estreitas em Pilocarpus pennatifolius. G- Parênquima em linhas estreitas em Diospyros inconstans. H- Parênquima em faixas largas em Sorocea bonplandii. (Fotos do autor). 




FIGURA 4 - Tipos de células parenquimáticas e variabilidade de cristais nas madeiras sul-rio-grandenses. A- Células oleíferas no parênquima axial de Ocotea pulchella, vistas transversalmente (seta). B- Parênquima exclusivamente seriado, com mais de 4 células, em Calyptranthes concinna. C e D- Parênquima eminentemente fusiforme em Lonchocarpus nitidus e Calliandra foliolosa, respectivamente. E- Cristais prismáticos e drusas nos raios de Acanthosyris spinescens (seta). E- Pequenos cristais aciculares nos raios de Baccharis longoattenuata. F- Cristais em grandes idioblástos no parênquima axial de Coccoloba cordata. G- Séries cristalíferas longas nas fibras de Allophylus guaraniticus. (Fotos do autor). 
O quantitativo de espécies com parênquima axial ausente ou raro é inferior ao que tem sido atribuído na literatura para a flora mundial, mas não difere muito do mencionado para a flora brasileira de latitude semelhante. Segundo Alves e Angyalossy-Alfonso (2002), na região sul do Brasil o percentual de espécies com parênquima axial ausente ou raro é de cerca de $9,2 \%$, bem próximo, portanto, ao verificado neste estudo (10\%). Já, no tocante à flora mundial, Wheeler et al. (2007) calcularam um valor em torno de $14 \%$, chegando a $33 \%$ no caso na região Temperada da América do Sul. Tanto na flora brasileira quanto na mundial o percentual de espécies com parênquima ausente ou raro mostra-se, via de regra, maior na região extratropical, tendência confirmada pelo presente estudo. Com exceção da flora da Mata Atlântica do Rio de Janeiro e da Bahia, investigadas por Barros e Callado (1997) e Barros et al. (2001, 2003), o percentual de espécies com parênquima ausente ou raro é inferior ao encontrado, girando em torno de $6 \%$ ou menos, com raras exceções, incluindo os valores calculados por Alves e Angyalossy-Alfonso (2002). Salienta-se que se trata aqui de tipo ou distribuição e não de abundância de parênquima axial, a qual será tema de discussão mais adiante. As diferenças encontradas em relação à flora da Mata Atlântica podem ser atribuídas à composição florística local ou questões de amostragem. Isso porque a ausência de parênquima axial é mais comum em certas famílias e gêneros, a exemplo de Salicaceae, Rubiaceae e Phyllanthaceae, entre outras, de modo que a maior ou menor ocorrência/inclusão de representantes destes grupos pode interferir no resultado final.

Ainda em relação a esse assunto, não é novidade na literatura que em madeiras onde o parênquima axial é raro ou ausente tende a aumentar significativamente a incidência de fibras septadas, uma vez que elas podem substituir funcionalmente aquele tecido (Carlquist, 1975; Wheeler e Baas, 1991; Carlquist, 2001; Wheeler et al., 2007). No presente estudo constatou-se que dez das doze espécies com parênquima axial ausente ou raro também apresentam fibras septadas na madeira, em consonância com o que tem sido referido na literatura especializada. Nem todas as espécies com fibras septadas têm, no entanto, parênquima axial ausente ou raro obrigatoriamente, tampouco em proporção equivalente a relação inversa dos dois tecidos. Entre as espécies investigadas, 31 apresentam septos em fibras, mas apenas 12 contam com parênquima ausente ou raro (Tabela 1).

Quanto à altura das séries parenquimáticas, Metcalfe e Chalk (1983) e Carlquist (2001) atribuem a maioria das Dicotiledôneas séries com até 7-8 células, o que está de acordo com o observado no presente estudo, no qual se constatou que séries parenquimáticas longas, com mais de 8 células, raramente ocorrem. A prevalência de espécies com séries parenquimáticas de até 8 células é também corroborada pela análise da flora mundial, onde são amplamente predominantes (Wheeler et al., 2007). Por outro lado, na flora mundial mostram-se mais frequentes as séries parenquimáticas de 2-4 do que aquelas de 4-8 células, inclusive na região extra-tropical, ao contrário do Rio Grande do Sul onde predominam as séries com mais de 4 células de altura. Em relação à flora brasileira, o comportamento é semelhante ao descrito para a flora mundial, com exceção do Rio de Janeiro, onde se verifica predomínio das séries parenquimáticas longas, com mais de 8 células de altura, como se pode confirmar nos trabalhos de Barros e Callado (1997) e Barros et al. (2001, 2003).

A altura das séries de parênquima axial em número de células tem, aparentemente, uma forte vinculação taxonômica. Citam-se, como exemplo, as famílias Leguminosae e Myrtaceae, que são os dois grupos com maior número de representantes incluídos neste trabalho. Independentemente da região brasileira ou formação vegetacional onde ocorrem, a maioria das Leguminosas apresenta séries parenquimáticas com até 4 células, ao contrário das Mirtáceas que geralmente desenvolvem séries mais longas. Cabe salientar que as séries paren- 
quimáticas tendem a tornar-se mais curtas em espécies especializadas, devido à relação entre o seu comprimento e o das iniciais cambiais (Metcalfe e Chalk, 1983). Além das Leguminosas, já citadas, costumam apresentar estrutura altamente especializada vários gêneros e espécies de Bignoniaceae e Asteraceae, entre outros. A maior ou menor ocorrência e/ou amostragem de espécies de determinados grupos taxonômicos, por conseguinte, pode influenciar o padrão de distribuição do caráter no conjunto das Dicotiledôneas de determinada região, o que explica, ao menos em parte, as diferenças observadas.

Em relação ao comprimento linear das séries parenquimáticas, há poucos dados disponíveis para comparações. Para a flora da Mata Atlântica do Rio de Janeiro, investigada por Barros e Callado (1997) e Barros et al. (2001, 2003), o comprimento médio linear é superior a 500 um, maior, portanto, do que o calculado para as madeiras sul-rio-grandenses $(362 \mu \mathrm{m})$. Além da questão taxonômica acima discutida, essa diferença, que também se manifesta individualmente nas famílias, como Myrtaceae, Euphorbiaceae e Leguminosae, pode ser resultado da influência latitudinal, que tende a produzir um encurtamento no tamanho das células à medida que as espécies afastam-se dos trópicos, como demonstrado em inúmeros trabalhos de Anatomia Ecológica (Carlquist, 1975; Baas et al., 1983; Baas e Schweingruber, 1987; Noshiro e Baas, 2000; Lens et al., 2004).

Acerca do volume ocupado pelo parênquima axial na madeira, cabe salientar de início que é difícil fazer uma comparação com os demais trabalhos, uma vez que a determinação deste caráter anatômico, nas poucas vezes em que é realizada, não segue um critério único e objetivo. Estudos têm demonstrado que espécies com parênquima axial abundante são mais frequentes nos trópicos do que em regiões extratropicais, ao contrário daquelas com tecido parenquimático escasso (Baas, 1973; Baas, 1982; Wheeler e Baas, 1991; Wheeler et al., 2007). Isso se mostra válido inclusive para a flo- ra brasileira, conforme se pode confirmar no trabalho de Alves e Angyalossy-Alfonso (2002). No presente estudo, constatou-se que a incidência de espécies com pouco ou nenhum parênquima axial na madeira é elevada e maior em comparação àquela com parênquima axial abundante. Embora não se possa fazer uma comparação direta com os demais trabalhos, como já salientado, esse resultado serve ao menos como indicativo de que tendem a se confirmar as conclusões acima sobre o tema.

Resta discutir, por fim, a elevada ocorrência de cristais nas madeiras sul-rio-grandenses. Cristais, principalmente de oxalato de cálcio, são muito comuns em Angiospermas, podendo ser encontrados em quase todos os tecidos e células lenhosas, inclusive no interior dos vasos, onde aparecem associados aos tilos (Appezzatoda-Gloria e Carmello-Guerreiro, 2006). Nas espécies investigadas, os cristais foram observados no parênquima axial, raios e, menos comumente, nas fibras, mas não no interior dos vasos. Segundo Wheeler et al. (1989), os cristais podem apresentar-se de diversas formas: ráfides, drusas, estiloides, areia cristalina, cristais aciculares e cristais prismáticos, sendo esta última a mais comum em madeiras, fato confirmado pelo presente estudo, onde observou-se cristais quase exclusivamente do tipo prismáticos (Figura 2).

A presença ou não de cristais, tipo, tamanho, bem como localização na madeira pode ser útil à classificação e/ou identificação de determinados grupos, podendo estar consistentemente presentes em alguns e ausentes em outros, ou podendo, ainda, ter natureza ocasional (Wheeler et al., 1989). Estas considerações sobre a incidência e uso taxonômico de cristais são confirmadas perfeitamente pela análise das madeiras sul-rio-grandenses. Em Fabaceae e Myrtaceae, por exemplo, os cristais geralmente ocorrem no parênquima axial; em Rhamnaceae, estão praticamente restritos aos raios; e nas Rubiaceae, são completamente ausentes. Considerando os grupos taxonômicos inferiores, são bons exemplos os gêneros Campomanesia e Eugenia, ambos 
integrantes de Myrtaceae: no primeiro caso, os cristais estão sempre ausentes, ao contrário do segundo, onde ocorrem invariavelmente. A natureza ocasional foi observada nas madeiras de Mimosa incana, Mimosa pilulifera, Blepharocalyx salicifolius, entre outros representantes da família da murta. Merece destaque, ainda, pela singularidade e valor taxonômico, a ocorrência já referida de drusas e cristais aciculares no parênquima axial de algumas espécies, bem como os cristais em grandes idioblástos das madeiras de Acacia caven, Coccoloba cordata, Psidum cattleianum e diversas outras Mirtáceas, principalmente do gênero Eugenia.

Wheeler et al. (2007), em estudo de tendência anatômicas na flora mundial, referem a ocorrência de cristais prismáticos em $48 \%$ das espécies, um percentual inferior ao calculado para o Rio Grande do Sul, que gira em torno de $61 \%$. Ainda de acordo com os autores, existe uma tendência para o aumento da incidência de cristais em direção aos trópicos e ambientes xéricos, hipótese também aventada em outros trabalhos disponíveis na literatura (Baas, 1973; BarajasMorales, 1985; Wilkins e Papassotiriou, 1989; Lens et al., 2004; Lima et al., 2009). Os resultados do presente estudo, todavia, não contribuem positivamente com esta tendência. Ao contrário do sugerido, o quantitativo de espécies com cristais na flora sul-rio-grandense mostrase, com frequência, superior ao calculado para a flora de outras regiões brasileiras de latitudes menores, cujos valores variam de 42-66\% (Barros e Callado, 1997; Cury, 2001; Barros et al., 2001, 2003; Mattos et al., 2003; Muñiz et al., 2007; Sonsin-Oliveira, 2010; Trevizor, 2011; Silva, 2013).

Vasconcellos et al. (1996), em estudo detalhado sobre a ocorrência de inclusões minerais nas madeiras da Amazônia, encontraram cristais em não mais que $34 \%$ das espécies, resultado que contraria igualmente as conclusões de Wheeler et al. (2007), considerando o percentual obtido na flora gaúcha. Em verdade, nem mesmo os próprios resultados de Wheeler et al.
(2007) corroboram a referida tendência, pelo menos no caso da América do Sul, uma vez que, conforme os dados disponíveis, é praticamente idêntico o percentual de espécies com cristais, tanto na região tropical quanto na temperada (cerca de 50\%). Como explica silva (2013), cristais, assim como outras substâncias ergásticas, são produtos do metabolismo secundário das plantas, e é de se esperar que em regiões de baixas latitudes, onde as taxas metabólicas são mais elevadas, haja maior propensão a sua formação. Esse, todavia, não é o único fator, sendo determinantes também a disponibilidade de certos minerais no solo e o metabolismo de cada espécie. A incidência de cristais nas madeiras de determinada região, por conseguinte, depende da interação de diversos fatores, além da latitude e disponibilidade hídrica, o que pode justificar as diferenças observadas em relação à flora mundial.

\section{CONCLUSÕES}

As espécies sul-rio-grandenses exibem grande variabilidade no parênquima axial. Os parênquimas paratraqueal e seriado são predominantes. O arranjo apotraqueal difuso e/ou difuso-em-agregados é o mais comum. A altura do parênquima axial geralmente não ultrapassa 8 células e $500 \mu \mathrm{m}$, sendo as séries com mais de 4 células um pouco mais frequentes comparado as demais. A maioria das espécies têm quantidade intermediária de tecido parenquimático, sendo o parênquima escasso mais comum que o abundante. É muito frequente a ocorrência de cristais, associados principalmente ao parênquima axial e/ou raios. Esta característica, juntamente com os parênquimas paratraqueal e seriado, são as únicas que ocorrem em 50\% ou mais das espécies investigadas. Do ponto de vista taxonômico, destaca-se, pela distribuição mais restrita, a presença de cristais em fibras, o parênquima axial ausente ou raro, a ocorrência de células oleíferas, drusas e cristais aciculares, bem como o parênquima eminentemente fusiforme ou marginal. Embora haja divergências, como no caso da incidência de cristais, os 
padrões observados refletem, via de regra, tendências anatômicas condizentes com o posicionamento latitudinal do Estado. Além da latitude, as diferenças observadas podem ser atribuídas, ao menos em parte, a questões relacionadas à amostragem ou composição florística local. No caso do Rio Grande do Sul, a grande quantidade de Leguminosas e Mirtáceas amostradas são certamente determinantes para o padrão anatômico geral. Não se pode ignorar, todavia, que são justamente estas as duas famílias botânicas com o maior número de representantes na flora lenhosa do Estado (Sobral et al., 2006).

\section{REFERÊNCIAS BIBLIOGRÁFICAS}

ALVES, E.S.; ANGYALOSSY-ALFONSO, V. Ecological trends in the wood anatomy of some brazilian species. 1. Growth rings and vessels. IAWA Journal, v. 21, p. 3-30, 2000.

ALVES, E.S.; ANGYALOSSY-ALFONSO, V. Ecological trends in the wood anatomy of some brazilian species. 2. Axial parenchyma, rays and fibers. IAWA Journal, v. 23, n. 4, p. 391-418, 2002.

APPEZZATO-DA-GLÓRIA, B.; CARMELLOGUERREIRO, S.M. Anatomia vegetal. 2 ed. Viçosa: Editora UFV, 2006. 438p.

ARTICO, M.; BALDIN, T.; DENARDI, L.; SANTOS, S.R. Descrição anatômica do xilema secundário de Tabernaemontana catharinensis A. DC. (Apocynaceae). Balduinia, Santa Maria, n. 24, p. 10-15, 2010.

ÁVILA, A.; GIONGO, C.; SCHEEL-YBERT, R. Anatomia do lenho carbonizado de 10 espécies nativas da Planície Costeira do Rio Grande do Sul - Subsídio a pesquisas Arqueobotânicas e Paleontológicas. Cadernos do Lepaarq, v.14, n.27, p. 481-511, 2017.

BAAS, P. The wood anatomical range in Ilex (Aquifoliaceae) and its ecological and phylogenetic significance. Blumea, v. 21, n. 2, p. 193-258, 1973.

BAAS, P. Systematic, Phylogenetic and ecological wood anatomy - History and perspectives. Martinus Nijhoff Publishers, The Hague, 1982. 252p.
BAAS, P.; SCHWEINGRUBER, F.H. Ecological trends in wood anatomy of trees, shrubs and climbers from Europe. IAWA Bulletin, v. 8, p. 245-274, 1987.

BAAS, P.; WERKER, E.; FAHN, A. Some ecological trends in vessel characters. IAWA Bulletin, v. 4 , p. 141-160, 1983.

BALDIN, T.; MARCHIORI, J.N.C. Anatomia da madeira de Albizia inundata (mart.) Barneby ex J.W. Grimes (Fabaceae). Balduinia, Santa Maria, n. 46, p. 25-31, 2014.

BALDIN, T.; DENARDI, L.; TREVISAN, R.; NISGOSKI, S. Anatomia do lenho de Condalia buxifolia Reissek (Rhamnaceae). Balduinia, Santa Maria, n. 32, p. 12-16, 2011.

BARAJAS-MORALES, J. Wood structural differences between trees of two tropical forests in Mexico. IAWA Bulletin, v. 6, n. 4, p. 355-364, 1985.

BARROS, C.F.; CALLADO, C.H. Madeiras da Mata Atlântica. Anatomia do lenho de espécies ocorrentes nos remanescentes florestais do estado do Rio de Janeiro, Brasil. Volume 1. Rio de Janeiro: Instituto de Pesquisas Jardim Botânico do Rio de Janeiro, 1997. 86p.

BARROS, C.F.; CALLADO, C.H.; MARCON, M.L.; COSTA, C.G.; CUNHA, M.; LIMA, H.R.P.; MARQUETE, O. Madeiras da Mata Atlântica. Anatomia do lenho de espécies ocorrentes nos remanescentes florestais do estado do Rio de Janeiro, Brasil. Volume 2. Rio de Janeiro: Instituto de Pesquisas Jardim Botânico do Rio de Janeiro, 2001. 94p.

BARROS, C.F.; CALLADO, C.H.; CUNHA, M.; MARCON, M.L.F.; TAMAIO, N.; MARQUETE, O.; COSTA, C.G. Madeiras da Mata Atlântica. Anatomia do lenho de espécies ocorrentes nos remanescentes florestais do estado do Rio de Janeiro, Brasil. Volume 3. Rio de Janeiro: Instituto de Pesquisas Jardim Botânico do Rio de Janeiro, 2003. 86p.

BRASIL, Ministério da Agricultura. Departamento Nacional de Pesquisa Agropecuária. Divisão Pedológica. Levantamento de reconhecimento dos solos do estado do Rio Grande do Sul. (Boletim técnico n. 30). Recife, PE, 1973. 431p.

BRAUN, H.J. The significance of the accessory tissues of the hydrosystem for osmotic water shifting as the second principle of water ascent, 
with some thoughts concerning the evolution of trees. Iawa Bulletin, v.5, n.4, p. 275-294, 1984.

CARLQUIST, S. Ecological strategies of xylem evolution. Berkeley: University of California Press, 1975. 259p.

CARLQUIST, S. Comparative Wood Anatomy. Systematic, ecological and evolutionary aspects of Dicotyledon wood. Berlin: Springer-Verlag, 2001. 446p.

CARLQUIST, S.; HOEKMAN, D.A. Ecological wood anatomy of the woody southern californian flora. IAWA Bulletin, v. 6, n. 4, p. 319-347, 1985.

CARNIELETTO, C.; MARCHIORI, J.N.C. Anatomia da madeira de Mimosa eriocarpa Benth. Ciência Florestal, Santa Maria, v. 3, n. 1, p. 107120, 1993.

COSTA, H.W.D.; BALDIN, T.; DENARDI, L.; DE CARLI, L.; TREVISAN, R.; MARCHIORI, J.N.C. Anatomia do lenho de Maytenus cassineformis reissek (Celastraceae). Balduinia, Santa Maria, n. 50, p. 29-33, 2015.

CURY, G. Descrição da estrutura anatômica do lenho e sua aplicação na identificação de espécies arbóreas do cerrado e da mata atlântica do estado de São Paulo. Piracicaba: ESALQ, 2002. 125 f. Dissertação (Mestrado) - Universidade de São Paulo: Escola Superior de Agricultura Luiz de Queiroz.

DENARDI, L. Anatomia e flexibilidade do caule de quatro espécies lenhosas para o manejo biotécnico de cursos de água. Santa Maria: UFSM, 2007. 113 p. Tese (Doutorado em Manejo Florestal) - Universidade Federal de Santa Maria.

DENARDI, L.; MARCHIORI, J.N.C.; FERREIRA, M.R. Anatomia da madeira de Azara uruguayensis (Speg.) Sleum. Balduinia, Santa Maria, n. 5, p. 17-22, 2005.

DENARDI, L.; MARCHIORI, J.N.C.; SANTOS, S.R.. Anatomia da madeira de Salix humboldtiana Willd. (Salicaceae). Balduinia, Santa Maria, n. 11, p. 27-31, 2007.

GERALDI, V.; DENARDI, L.; LANZ, C.J.; TREVIZAN, R. Análise preliminar do lenho de Sorocea bonplandii (Baill.) W.C. Burger, Lanjouw ex Boer (Moraceae). Anais 29 Jornada Acadêmica Integrada (JAI), Santa Maria, 2014.

GOMES, A.V.; MARCHIORI, J.N.C.; TEIXEIRA,
L.L.; SCHAITZA, E.G; STOFELLA, D.R.E. Anatomia da madeira de Citharexylum solanaceum Cham. (Verbenaceae). Balduinia, Santa Maria, n. 12, p. 13-25, 2008.

GUMA, R.; BALDIN, T.; DENARDI, L.; HASELEIN, C.R.; MARCHIORI, J.N.C. Anatomia da madeira de Tetrorchidium rubrivenium Poepp. ex Endl. (Euphorbiaceae). Balduinia, Santa Maria, n. 47, p. 12-18, 2015.

LENS, F; LUTEYN, J.L.; SMETS, E; JANSEN, S. Ecological trends in the wood anatomy of Vaccinioideae (Ericaceae s.1.). Flora, 199, 309319, 2004.

LIMA, R.S.; OLIVEIRA, P.L.; RODRIGUES, L.R. Anatomia do lenho de Enterolobium contortisiliquun (Vell.) Morong. (LeguminosaeMimosoideae) ocorrente em dois ambientes. Revista Brasileira de Botânica, v. 32, n. 2, 361374, 2009.

LINDORF, H. Eco-anatomical wood features of species from a very dry tropical forest. IAWA Bulletin, v. 15, p. 361-376, 1994.

LEÓN, W. Anatomía ecológica del xilema secundario de un bosque seco tropical de Venezuela. Acta Botánica Venezuelica, v. 28, n. 2, p. 1-22, 2005.

MACCARI, A.; MARCHIORI, J.N.C. Estudo anatômico do xilema secundário de Mimosa sparsa Benth. Ciência Florestal, Santa Maria, v. 4, p. 145-155, 1994.

MACHADO, P.F.S.; SIEGLOCH, A.M.; BALDIN, T.; COLDEBELlA, R.; PEDRAZZI, C. MARCHIORI, J.N.C. Anatomia do lenho de Maclura tinctoria D. Don ex Steud. Balduinia, Santa Maria, n. 49, p. 29-33, 2015.

MALUF, J.R.T. Nova classificação climática do Estado do Rio Grande do Sul. Revista Brasileira de Agrometeorologia, Santa Maria, v. 8, n. 1, p. 141-150, 2000.

MARCHIORI, J.N.C. Estudo anatômico do xilema secundário e da casca de Acacia recurva Benth. (Leguminosae Mimosoideae). Ciência e Natura, Santa Maria, v. 4, p. 95-105, 1982.

MARCHIORI, J.N.C. A estrutura do xilema secundário de Mimosa daleoides Benth. (Leguminosae Mimosoideae). Ciência e Natura, Santa Maria, v. 4, p. 107-113, 1982.

MARCHIORI, J.N.C. Anatomia da madeira de Maba inconstans (Jacq.) Gris. (Ebenaceae). Ciência e Natura, Santa Maria, v. 5, p. 153-160, 1983. 
MARCHIORI, J.N.C. Estudo anatômico do xilema secundário de Cassia corymbosa Lam. (Leguminosae Caesalpinioideae). Ciência e Natura, Santa Maria, v. 5, p. 179-186, 1983.

MARCHIORI, J.N.C. Anatomia descritiva da madeira do pau-de-sabão, Quillaja brasiliensis (St. Hil. et Tul.) Mart., Rosaceae Spiraeoideae. Rev. Centro de Ciências Rurais, Santa Maria, v. 14, n. 1, p. 33-41, 1984.

MARCHIORI, J.N.C. Anatomia descritiva das madeiras do gênero Calliandra Benth., nativas no estado do Rio Grande do Sul. In: Anais do V Congresso Florestal Estadual, Nova Prata, RS, 1984. p. 841-870.

MARCHIORI, J.N.C. Anatomia descritiva da madeira de Guarea lessoniana A. Juss. Ciência e Natura, Santa Maria, v. 7, p. 63-71, 1985.

MARCHIORI, J.N.C. Anatomia da madeira de $M i$ mosa cruenta Benth. (Leguminosae Mimosoideae). Ciência e Natura, Santa Maria, v. 7, p. 73-81, 1985.

MARCHIORI, J.N.C. Anatomia descritiva das madeiras do gênero Prosopis L., nativas no estado do Rio Grande do Sul. Ciência e Natura, Santa Maria, v. 7, p. 83-97, 1985.

MARCHIORI, J.N.C. Anatomia descritiva da madeira de quebracho-branco (Aspidosperma quebracho-blanco Schltdl.). Ciência e Natura, Santa Maria, v. 7, p. 99-106, 1985.

MARCHIORI, J.N.C. Estudo anatômico da madeira de Acanthosyris spinescens (Mart. et Eichl.) Gris. (Santalaceae). Ciência e Natura, Santa Maria, v. 7, p. 107-118, 1985.

MARCHIORI, J.N.C. Estudo anatômico da madeira de grapiapunha-do-banhado, Lonchocarpus nitidus (Vogel) Benth. Ciência e Natura, Santa Maria, v. 7, p. 119-127, 1985.

MARCHIORI, J.N.C. Estudo anatômico da madeira de Chomelia obtusa Cham. et Schltdl. Ciência e Natura, Santa Maria, v. 8, p. 87-94, 1986.

MARCHIORI, J.N.C. Estudo anatômico da madeira de Pilocarpus pennatifolius Lam. (Rutaceae). Ciência e Natura, Santa Maria, v. 8, p. 95-103, 1986.

MARCHIORI, J.N.C. Anatomia do xilema secundário de Indigofera suffruticosa Miller. Ciência e Natura, Santa Maria, v. 8, p. 105-114, 1986.

MARCHIORI, J.N.C. Estudo anatômico da madeira do veludinho, Guettarda uruguensis Cham. et
Schltdl. Ciência e Natura, Santa Maria, v. 8, p. 115-123, 1986.

MARCHIORI, J.N.C. Anatomia descritiva da madeira de canela-de-veado, Helietta longifoliata Britton, Rutaceae. Rev. Centro de Ciências Rurais, Santa Maria, v. 15, n. 4, p. 335-344, 1985.

MARCHIORI, J.N.C. Estudo anatômico da madeira de Lonchocarpus leucanthus Burk. (Leguminosae Faboideae). Rev. Centro de Ciências Rurais, Santa Maria, v. 15, n. 4, p. 345354, 1985.

MARCHIORI, J.N.C. Anatomia da madeira de catiguá-vermelho, Trichilia hieronymi Griseb. (Meliaceae). Rev. Centro de Ciências Rurais, Santa Maria, v. 15, n. 4, p. 355-365, 1985.

MARCHIORI, J.N.C. Anatomia descritiva da madeira do amarilho, Terminalia australis Camb. (Combretaceae). Rev. Centro de Ciências Rurais, Santa Maria, v. 16, n. 4, p. 329-340, 1986.

MARCHIORI, J.N.C. Estudo anatômico da madeira do mata-olho, Pouteria salicifolia (Spreng.) Radlk. Rev. Centro de Ciências Rurais, Santa Maria, v. 16, n. 4, p. 341-352, 1986.

MARCHIORI, J.N.C. Anatomia da madeira do limoeiro-do-mato, Randia armata (Sw.) DC. Rev. Centro de Ciências Rurais, Santa Maria, v. 17, n. 1-2, p. 39-48, 1987.

MARCHIORI, J.N.C. Anatomia da madeira de Acacia nitidifolia Speg. (Leguminosae Mimosoideae). Ciência Florestal, Santa Maria, v. 1, n.1, p. 46-63, 1991.

MARCHIORI, J.N.C. Anatomia da madeira e casca do espinilho, Acacia caven (Mol.) Mol. Ciência Florestal, Santa Maria, v. 2, n. 1, p. 27-47, 1992.

MARCHIORI, J.N.C. Anatomia da madeira e casca do maricá, Mimosa bimucronata (DC.) O. Kuntze. Ciência Florestal, Santa Maria, v. 3, n. 1, p. 85-106, 1993.

MARCHIORI, J.N.C. Estudo anatômico do xilema secundário de Acacia ibirocayensis Marchiori (Leguminosae Mimosoideae). Ciência e Natura, Santa Maria, v. 15, p. 149-159, 1993.

MARCHIORI, J.N.C. Anatomia da madeira e casca de Acacia tucumanensis Gris. Ciência e Natura, Santa Maria, n. 16, p. 85-104, 1994.

MARCHIORI, J.N.C. Anatomia da madeira do angico-branco, Albizia austrobrasilica Burk. Ciência e Natura, Santa Maria, v. 17, p. 75-86, 1995. 
MARCHIORI, J.N.C. Anatomia da madeira e casca da bracatinga, Mimosa scabrella Benth. Ciência e Natura, Santa Maria, v. 17, p. 115-132, 1995.

MARCHIORI, J.N.C. Anatomia do xilema secundário de Mimosa incana (Spreng.) Benth. Ciência Florestal, Santa Maria, v. 6, n. 1, p. 53-63, 1996.

MARCHIORI, J.N.C. Anatomia do xilema secundário de Mimosa uruguensis Hook. et Arn. Ciência e Natura, Santa Maria, v. 18, p. 103-115, 1996.

MARCHIORI, J.N.C. Anatomia do xilema secundário de Mimosa berroi Burk. Ciência e Natura, Santa Maria, v. 18, p. 117-129, 1996.

MARCHIORI, J.N.C. Anatomia da madeira de Acacia bonariensis Gill. ex Hook. et Arn. Ciência Rural, Santa Maria, v. 26, n. 2, p. 209-216, 1996.

MARCHIORI, J.N.C. Fitogeografia do Rio Grande do Sul. Enfoque histórico e sistemas de classificação. Porto Alegre: EST, 2002. 118p.

MARCHIORI, J.N.C. Estudo anatômico da madeira de Handroanthus pulcherrimus (Sandwith) S. Grose. Balduinia, Santa Maria, n. 19, p. 10-13, 2009.

MARCHIORI, J.N.C.; DENARDI, L. Anatomia da madeira de Escallonia megapotamica Sprengel. Balduinia, Santa Maria, n. 2, p. 19-24, 2005.

MARCHIORI, J.N.C.; DENARDI, L. Anatomia da madeira de Berberis laurina Billb. Balduinia, Santa Maria, n. 4, p. 25-29, 2005.

MARCHIORI, J.N.C.; FREITAS, A.M. Anatomia da madeira de Celtis pallida Torrey (Ulmaceae). Ciência e Natura, Santa Maria, v. 15, p. 137147, 1993.

MARCHIORI, J.N.C.; MUÑIZ, G.I.B. Estudo anatômico da madeira de Coccoloba cordata Cham. (Polygonaceae). Ciência e Natura, Santa Maria, v. 9, p. 87-95, 1987.

MARCHIORI, J.N.C.; MUÑIZ, G.I.B.. Estudo anatômico da madeira de Machaonia spinosa Cham. et Schltdl. (Rubiaceae). Ciência e Natura, Santa Maria, v. 9, p. 105-112, 1987.

MARCHIORI, J.N.C.; MUÑIZ, G.I.B. de. Estudo anatômico do xilema secundário de Mimosa trachycarpa Benth. Ciência Rural, Santa Maria, v. 27, n. 2, p. 223-228, 1997.

MARCHIORI, J.N.C.; MUÑIZ, G.I.B. Anatomia do xilema secundário de Mimosa pilulifera Benth.
Ciência Florestal, Santa Maria, v. 6, n. 1, p. 6575, 1997.

MARCHIORI, J.N.C.; OLIVEIRA, A.S. Anatomia da madeira de três espécies brasileiras de Baccharis L. (Asteraceae-Astereae). Balduinia, Santa Maria, n. 10, p. 1-10, 2007.

MARCHIORI, J.N.C.; POZZERA, F. Anatomia da madeira de Xylosma tweedianum Eichler (Flacourtiaceae). Ciência e Natura, Santa Maria, v. 19, p. 159-171, 1997.

MARCHIORI, J.N.C.; MUÑIZ, G.I.B.; SANTOS, S.R. Madeiras do Rio Grande do Sul 2 - Descrição microscópica de 35 espécies nativas. Santa Maria: Anaterra, 2010. 80p.

MARCHIORI, J.N.C.; OLIVEIRA-DEBLE, A.S.; DENARDI, L. Anatomia da madeira de duas espécies de Baccharis L. (Asteraceae Astereae). Balduinia, Santa Maria, n. 11, p. 1-8, 2007.

MATTOS, P.P.; TEIXEIRA, L.L.; SEITZ, R.A.; SALIS, M.S.; BOTOSSO, C.P. Anatomia de madeiras do Pantanal Mato-Grossense. Características microscópicas. Colombo: EMBRAPA Florestas. Corumbá: EMBRAPA Pantanal, 2003, $182 \mathrm{p}$.

MELO JUNIOR, J.C.F.; AMORIM, M.W.; SOFFIATTI, P. Comparative wood anatomy of Ficus cestrifolia (Moraceae) in two distinct soil conditions. Rodriguesia, v. 64, n.4, 2109-2118, 2018.

METCALFE, C.R.; CHALK, L. Anatomy of the Dicotyledons. Wood structure and conclusions of the general introdution. Oxford: Clarendon Press, 1983. 308p.

MUÑIZ, G.I.B.; SILVA, T.; CARNEIRO, M.E.; CALIXTO, D. Madeiras do municipio de Nova Maringá-MT. Características e utilização. Laboratório de Anatomia da Madeira (UFPR), Curitiba, 2007. 102p.

NOSHIRO, S.; BAAS, P. Latitudinal trends in wood anatomy within species and genera. Case study in Cornus S. L. (Cornaceae). American Journal of Botany, v. 87, n. 10, p. 1495-1506, 2000.

OLIVEIRA, A.S.; DEBLE, L.P.; MARCHIORI, J.N.C. Anatomia da madeira de duas espécies do gênero Heterothalamus Lessing (Asteraceae), nativas no Rio Grande do Sul. Ciência Florestal, Santa Maria, v. 15, n. 1, p. 9-19, 2005.

RADDATS, D.D.; MACHADO, P.F.S.; ROSA, R.C.; 
SOUSA, R.S.; SUTILI, F.J.; MARCHIORI, J.N.C. Anatomia da madeira de Aspidosperma riedelii Müll. Arg. (Apocynaceae). Balduinia, n. 62, p. 18-26, 2018.

RADDATS, D.D.; MACHADO, P.F.S.; ROSA, R.C.; DEWES, J.J.; SUTILI, F.J.; MARCHIORI, J.N.C. Anatomia do lenho de duas espécies de Lafoensia (Lythraceae). Balduinia, n. 63, p. 2029, 2018.

SANTOS, S.R.; MARCHIORI, J.N.C. Tendências anatômicas na flora sul-rio-grandense 1 - Elementos vasculares. Balduinia, Santa Maria, n. 21, p. 01-14, 2010.

SANTOS, S.R.; MARCHIORI, J.N.C. Madeiras do Rio Grande do Sul 4 - Descrição microscópica de 34 Mirtáceas nativas. Santa Maria: Anaterra, 2011. 80p.

SANTOS, S.R.; SIEGLOCH, A.M.; MARCHIORI, J.N.C. Anatomia da madeira de Ruprechtia Salicifolia (Cham. ex Schltdl.) C. A. Mey. (Polygonaceae). Balduinia, Santa Maria, n. 28, p. 27-32, 2011

SIEGLOCH, A.M.; MARCHIORI, J.N.C.; SANTOS, S.R. Anatomia do lenho de Cephalanthus glabratus (Spreng.) K. Schum. (RUBIACEAE). Balduinia, Santa Maria, n. 31, p. 20-26, 2011.

SIEGLOCH, A.M.; MARCHIORI, J.N.C.; SANTOS, S.R. Anatomia do lenho de Bernardia pulchella (Euphorbiaceae). Balduinia, Santa Maria, n. 34, p. 28-32, 2012.

SIEGLOCH, A.M.; MARCHIORI, J.N.C.; SANTOS, S.R. Estudo anatômico do lenho de Sapium haematospermum Müll. Arg (Euphorbiaceae). Balduinia, Santa Maria, n. 35, p. 27-31, 2012.

SIEGLOCH, A.M.; MARCHIORI, J.N.C.; SANTOS, S.R. Anatomia do lenho de duas espécies de Croton (Euphorbiaceae) do Rio Grande do Sul. Balduinia, Santa Maria, n. 38, p. 25-30, 2012.

SIEGLOCH, A.M.; MARCHIORI, J.N.C.; SANTOS, S.R. Anatomia do lenho de Allophylus guaraniticus (St.Hil.) Radlk. (Sapindaceae). Balduinia, Santa Maria, n. 39, p. 19-23, 2013.

SIEGLOCH, A.M.; MARCHIORI, J.N.C.; SANTOS, S.R. Anatomia do lenho de duas espécies de Aloysia (Verbenaceae). Balduinia, Santa Maria, n. 41, p. 27-33, 2013

SIEGLOCH, A.M.; MARCHIORI, J.N.C.; SANTOS, S.R. Estudo anatômico da madeira de Citharexylum montevidense Moldenke
(Verbenaceae). Balduinia, Santa Maria, n. 42, p. 27-32, 2013.

SIEGLOCH, A.M.; SANTOS, S.R.; MARCHIORI, J.N.C. Descrição anatômica do lenho de Brunfelsia australis Bentham (Solanaceae). Balduinia, Santa Maria, n. 20, p. 16-20, 2010.

SIEGLOCH, A.M.; SANTOS, S.R.; MARCHIORI, J.N.C. Estudo anatômico do lenho de Colliguaya brasiliensis Klotzsch EX Baill. (Euphorbiaceae). Balduinia, Santa Maria, n. 27, p. 27-33, 2011.

SIEGLOCH, A.M.; SANTOS, S.R.; MARCHIORI, J.N.C. Estudo anatômico do lenho de Colubrina glandulosa Perkins. Balduinia, Santa Maria, n. 29, p. 28-34, 2011.

SIEGLOCH, A.M.; SANTOS, S.R.; MARCHIORI, J.N.C. Estudo anatômico do lenho de Callisthene inundata Bueno, Nilson ex Magalhães. Balduinia, Santa Maria, n. 32, p. 07-11, 2011.

SILVA, M.S. Anatomia ecológica e potencial econômico da madeira de espécies nativas da Mata Atlântica, Serra da Jiboia, Bahia, Brasil. 2013. 167 p. Dissertação (Mestrado em Botânica) Universidade Estadual de Feira de Santana, Feira de Santana.

SOBRAL, M.; JARENKOW, J.A.; BRACK, P.; IRGANG, B.; LAROCCA, J.; RODRIGUES, R.S. Flora arbórea e arborescente do Rio Grande do Sul, Brasil. São Carlos: RiMA/Novo Ambiente, 2006. 350p.

SONSIN-OLIVEIRA, J. Anatomia da madeira de espécies de Cerrado sensu lato do estado de São Paulo. 2010. 159p. Tese (Doutorado em Ciências Agronômicas) - Universidade Estadual Paulista (UNESP), Botucatu.

TREVIZOR, T.T. Anatomia comparada do lenho de 64 espécies arbóreas de ocorrência natural na Floresta Tropical Amazônica no estado do Pará. 2011. 214p. Dissertação (Mestrado em Ciências) - Universidade de São Paulo: Escola Superior de Agricultura Luiz de Queiroz, Piracicaba.

VASCONCELLOS, F.J.; FREITAS, J.A.; SILVA, A.C. Observação microscópica de inclusões minerais no xilema de espécies tropicais da Amazônia. Acta Amazônica, v. 25, p. 55-68, 1996.

WHEELER, E.A.; BAAS, P. A survey of the fossil record for Dicotyledonous wood and its significance for evolutionary and ecological wood antomy. IAWA Bulletin, v. 12, n. 3, p. 275 332, 1991. 
WHEELER, E.A; BAAS, P.; GASSON, P.E. IAWA list of microscopic features for hardwood identificacion. IAWA Bulletin, v. 10, n. 3, p. 219332, 1989.

WHEELER, E.A; BAAS, P.; RODGERS, S. Variations in dicot wood anatomy: a global analysis based on the insidewood database. IAWA Journal, v. 28, n. 3, p. 229-258, 2007.
WILKINS, A.P.; PAPASSOTIRIOU, S. Wood anatomical variation of Acacia melanoxylon in relation to latitude. IAWA Bulletin, v.10, n.2, p. 201-207, 1989.

XAVIER, M.; MACHADO, P.F.S.; MARCHIORI, J.N.C. Anatomia do lenho de Cestrum strigilatum (Solanaceae). Balduinia, Santa Maria, n. 64, p. 59-63, 2018. 